\title{
DO ESTADO DESENVOLVIMENTISTA AO ESTADO REGULADOR? TRANSFORMAÇÃO, RESILIÊNCIA E COEXISTÊNCIA ENTRE DOIS MODOS DE INTERVENÇÃO
}

Resumo: Nas últimas décadas, a literatura registrou uma difusão do modelo regulatório, tanto em países desenvolvidos, como em países desenvolvimento, inclusive naqueles em que prevalecera uma intervenção desenvolvimentista. Como traço comum, diversos países realizaram reformas institucionais que estabeleceram as bases de um outro tipo de governança econômica. A despeito da matriz global do fenômeno, as mudanças institucionais são processadas no âmbito nacional. Assim, o resultado das reformas não é necessariamente um reflexo direto das agendas de organismos multilaterais. $\mathrm{Na}$ dimensão doméstica, fatores de resistência institucional (path dependence) podem impactar os desenhos institucionais e a governança econômica. A resiliência institucional está presente, entre outros, na doutrina jurídica, na aplicação das regras jurídicas pelos tribunais e também na sua mobilização pelos grupos de interesse. Por essa razão, a despeito do isomorfismo das agências e da convergência regulatória, a anatomia institucional da intervenção estatal adquire formatos institucionais diferentes entre os países e seus setores econômicos. Em termos analíticos, os diferentes ajustes entre o modelo regulatório propagado e a configuração jurídica local podem ser compreendidos pelos tipos: transformação, resiliência e coexistência. $O$ trabalho apresenta como exemplo reformas regulatórias ocorridas no sistema financeiro, em que prevaleceu a coexistência entre o arranjo precedente e a nova composição institucional.

Palavras-Chave: Estado Desenvolvimentista; Estado Regulador; Reforma Regulatória; Transformação; Resiliência; Coexistência; Sistema Financeiro.

\footnotetext{
${ }^{1}$ Professor da FGV Direito SP.
} 
DO ESTADO DESENVOLVIMENTISTA AO ESTADO REGULADOR? TRANSFORMAÇÃO, RESILIÊNCIA E COEXISTÊNCIA ENTRE DOIS MODOS DE INTERVENÇÃO

\title{
FROM DEVELOPMENTAL TO REGULATORY STATE? TRANSFORMATION, RESILIENCE AND COEXISTENCE BETWEEN TWO MODES OF REGULATION
}

\begin{abstract}
In the last decades, the literature has shown a diffusion of regulatory model, both in developed countries and in developing countries, even in those where a developmental arrangement prevailed. As a common feature, several countries have carried out institutional reforms that have laid the foundations for another type of economic governance. In spite of the global matrix of the phenomenon, countries processed institutional changes locally. Thus, the outcome of regulatory reforms is not a direct reflection of the multilateral agencies' agenda. In the domestic dimension, path dependence issues shape institutional designs and economic governance. One can find path dependence in legal doctrine, in the law enforcement by courts and also in interest groups' collective action. So, in spite of the trend toward regulatory convergence, state intervention's institutional anatomy acquires different formats among countries and economic sectors. In analytical terms, this paper employs three categories to describe the varieties of the interplay between global diffusion and local construction of the regulatory state: transformation, resilience, and coexistence. Ultimately, the paper presents regulatory reform that took place in the financial system as an illustration of this interplay, in which prevailed a coexistence between the precedent developmental arrangement and the novel regulatory design.
\end{abstract}

KEYWORDS: Developmental State; State Regulator; Regulatory Reform; Transformation; Resilience; Coexistence; Financial System. 


\section{REVISTA ESTUDOS INSTITUCIONAIS}

\section{INTRODUÇÃO}

Nas últimas décadas, com realce para o período compreendido entre 1995 e 2005. boa parte dos setores econômicos brasileiros foi obieto de reformas regulatórias que procuraram alterar o modo prevalecente de sua organizacão institucional. Até então, sua governanca econômica sustentava-se em um modo de intervencão desenvolvimentista, isto é, um modo de intervencão estatal assentado na alocacão dos recursos pelo Estado, seia por meio de regras especiais de captacão e de direcionamento do crédito, seia pela atuacão de bancos públicos e empresas estatais. Neste período, foram realizadas sucessivas reformas legais destinadas a aumentar a protecão dos investidores e assim fomentar um mercado privado para estas atividades. Os setores abrangidos por estar reformas compuseram um leque variado, que incluiu, entre outros, telecomunicações, energia, gás e petróleo e o sistema financeiro.

Ocorre, contudo, que estas reformas não eliminaram a composicão precedente. As empresas estatais, os bancos públicos, a regulacão direcionada do crédito e os mecanismos de poupanca compulsória seguiram em atividade no país, ladeados agora por novos marcos requlatórios e arranios institucionais. Além disso, o período estabelecido entre 2005 e 2015 registrou uma retomada do ativismo estatal (TRUBEK; COUTINHO; SCHAPIRO, 2012), do que decorreu uma sobreposicão entre os dispositivos do Estado desenvolvimentista e aqueles derivados da reforma regulatória. Entre outros, este é o caso das interfaces entre as agências independentes e as empresas estatais; do banco central autônomo com os bancos públicos suieitos a taxas especiais de iuros, e da legalizacão do processo administrativo coniugada com a permanência de conselhos de rebresentação corporativa, em especial na gestão das políticas industriais.

Diante disso, este trabalho procura apresentar o panorama conceitual que constitui as tensões da reforma regulatória. O propósito é apresentar um marco analítico que permita compreender as discrepâncias entre a difusão global de um modelo regulatório de intervencão econômica e a sua constituicão local. Em trabalhos anteriores descreveu-se as mudancas ocorridas nos setores econômicos, em funcão das reformas, e também as características do ativismo estatal (TRUBEK: COUTINHO; SCHAPIRO. 2013; SCHAPIRO; COUTINHO, 2013; COUTINHO; SCHAPIRO, 2013). Neste artigo, por sua vez, o obietivo é constituir um marco analítico que permita compreender o sentido, as tensões e o modo de acomodação local das reformas regulatórias.

Para isso, o trabalho apresentará inicialmente um contraste analítico entre dois modelos opostos de intervenção econômica, o Estado 


\section{DO ESTADO DESENVOLVIMENTISTA AO ESTADO REGULADOR? TRANSFORMAÇÃO, RESILIÊNCIA E COEXISTÊNCIA ENTRE DOIS MODOS DE INTERVENÇÃO}

Desenvolvimentista e o Estado Regulador (secão 2). Em sequida, resenhará a literatura sobre a difusão do modelo regulatório (secão 3), e apresentará um modelo de compreensão do modo de acomodacão das reformas regulatórias diante das resistências locais de economia política (secão 4). Será ainda apresentado o exemplo de reformas requlatórias ocorridas no sistema financeiro brasileiro, para assim ilustrar o modelo de compreensão das tensões existentes entre a difusão global do modelo requlatório e suas dinâmicas locais (secão 5). Por último, o artigo apresenta suas considerações finais (seção 6).

\section{ESTADO REGULADOR E ESTADO DESENVOLVIMENTISTA: DOIS TIPOS DE INTERVENÇÃO ECONÔMICA}

O Estado regulador e o Estado desenvolvimentista configuram dois tipos de intervenção pública na economia, constituídos por diferentes objetivos políticos, instrumentos de atuação e bases jurídicas. O contraste foi inicialmente apresentado por Chalmers Johnson (1982, p. 17-25) para assim identificar os traços singulares do modelo de Estado japonês, que, para o autor, seriam as variáveis explicativas do processo de desenvolvimento do país, a partir da década de 1920 e, sobretudo, no segundo pós-guerra.

Originalmente, o Estado regulador e o Estado desenvolvimentista são arranjos de economia política historicamente situados. No entanto, a despeito de sua pertinência a estes contextos, respectivamente o norteamericano e o japonês, variações do Estado regulador e do Estado desenvolvimentista têm sido replicadas em outros países e em outros tempos históricos. Nessa medida, o Estado regulador e o Estado desenvolvimentista podem ser compreendidos não só como fenômenos historicamente situados, mas também, analiticamente, como tipos de organização pública da economia, isto é, como "tecnologias de governança econômica".

Sendo assim, a literatura relaciona ambas as variedades de intervenção econômica a diferentes bases institucionais. A intervenção regulatória está associada a um modelo pluralista de governança administrativa, baseado em uma atividade burocrática legalizada e em um controle judicial ativo das decisões da administração pública (STEWART, 1975). A intervenção desenvolvimentista, por sua vez, é sustentada em delegações legislativas abertas, em decisões discricionárias, e em espaços restritos para o controle social da 


\section{REVISTA ESTUDOS INSTITUCIONAIS}

administração pública (UPHAM, 1987, p. 166-204; OHNESORGE, 2001; OHNESORGE, 2006, p. 108-122).

\section{Estado Regulador: legalismo e participação}

A base jurídica do Estado regulador é constituída por uma governança legalizada e sujeita à participação dos grupos de interesse. $\mathrm{O}$ Estado regulador é, portanto, um subproduto do que Kagan (2001, p. 911) denomina de legalismo adversarial. Nesse arranjo, a concentração de poderes no Executivo é combinada com os seguintes atributos: (i) delegação substantiva de competências regulatórias pelo Congresso, por meio de lei; (ii) incidência de normas processuais sobre as agências reguladoras, que estabelecem os marcos do devido processo regulatório, e (iii) revisão judicial dos atos da administração pública.

Não se trata de uma governança liberal, baseada apenas em disposições legislativas e no controle judiciário ex post dos danos e prejuízos sofridos. A constituição da burocracia reguladora acarreta necessariamente poderes discricionários para o Executivo, essa é aliás a razão da constituição deste modo de intervenção. No entanto, os poderes de ação e a flexibilidade da intervenção econômica são mediados pelas leis. Isto é, a discricionariedade normativa é exercida dentro dos parâmetros da legalidade e encontra seus freios e contrapesos na atuação do Congresso e na revisão judicial.

Nesse desenho, o Congresso exerce o papel de principal político, isto é, de órgão de delegação dos poderes exercidos pela burocracia. A burocracia regulatória, por sua vez, é o agente, ou seja, é o ator encarregado de desempenhar $\mathrm{o}$ mandato $\mathrm{e}$ atender às condições processuais que lhe foram atribuídos pelo principal. A função de principal é exercida tanto por meio da formulação de leis, que conformam a atuação da burocracia, como por meio de expedientes ex post, destinados à fiscalização dos poderes delegados. Este é o caso das comissões parlamentares de investigação, da convocação de autoridades para explicações públicas e da eventual punição dos reguladores pela redução de seu orçamento, em função dos resultados apresentados.

Em relação às leis, o Congresso, na qualidade de principal, maneja duas possibilidades: as leis substantivas e as processuais. As leis substantivas são as que constituem o mandato de atuação da burocracia e disciplinam assim os parâmetros das políticas públicas a serem implementadas pelos órgãos reguladores. No Estado regulador, a atribuição de competência não ocorre de forma aberta: entre os poderes normativos do Executivo e a delegação congressual há balizas que tornam inteligível tanto o poder de ação das agências reguladoras como 


\section{DO ESTADO DESENVOLVIMENTISTA AO ESTADO REGULADOR? TRANSFORMAÇÃO, RESILIÊNCIA E COEXISTÊNCIA ENTRE DOIS MODOS DE INTERVENÇÃO}

a sua jurisdição. Esse quadro é complementado pelas leis processuais, que dispõem sobre os ritos, ônus e procedimentos a serem observados pela burocracia regulatória. Entre outros temas, as leis de processo administrativo tratam de temas como: (i) a alocação do ônus da prova entre as partes; (ii) o padrão de prova exigido para uma decisão administrativa; (iii) a forma de participação dos interessados; e (iv) o ônus de motivação exigido da autoridade ao decidir um caso ou regular uma atividade (MCCUBBINS; NOLL; WEINGAST, 1987; 1989).

Nesse ponto, a literatura de teoria política positiva aponta as regras processuais como um mecanismo de desenho e de controle da burocracia que é capaz de reforçar o monitoramento do Congresso e também do Judiciário sobre os reguladores (MCCUBBINS; NOLL; WEINGAST, 1987; 1989). Segundo essa interpretação, ao formalizar o rito e o ônus decisório da administração, as normas processuais permitem que os grupos de interesse e seus representantes políticos precavejam-se de uma atuação inesperada da burocracia. Sendo assim, as decisões administrativas devem seguir um roteiro pré-ordenado, com regras de publicidade sobre novos regulamentos, disposições sobre o tratamento a ser dado às reações dos interessados e uma ampla motivação das decisões tomadas. Evita-se assim o insulamento burocrático tendente à opacidade e à supremacia administrativa.

O recurso à legalidade processual e à legalidade substantiva na delegação das competências habilitam o caráter participativo deste modo de governança. De um lado, as regras de processo, ao instituírem os procedimentos de audiência e consulta pública, habilitam a disputa de interesses entre grupos rivais, que atuam de forma adversarial na formulação regulatória. De outro, a formalidade das competências e dos métodos de decisão, baseados em regras e procedimentos, atribuem ao judiciário um poder de revisão da regulação (MAJONE, 1997, p. 156). Um exemplo disso é o rito de "notice and comment", que impõe às agências reguladoras tanto o dever de anunciar previamente a disposição de introduzir um novo dispositivo regulatório, como a obrigação de colher a reação dos interessados e de motivar a eventual rejeição das propostas apresentadas. A sua inobservância, seja no que tange ao anúncio prévio, seja na desconsideração das participações, pode resultar em uma impugnação judicial da decisão administrativa (GERSEN, 2010, p. 342344; BIGNAMI, 2012, p. 16-20).

Esse modo de organização administrativa favorece, portanto, uma forma particular de representação dos interesses, que é o pluralismo político (BIGNAMI, 2012, p. 16-20). Trata-se de um modo de organização 


\section{REVISTA ESTUDOS INSTITUCIONAIS}

JULHO/DEZEMBRO - ISSN 2447-5467

que conta com a espontaneidade e a voluntariedade dos grupos sociais. Nesse modelo, prevalece a liberdade de associação e a capacidade de representação é testada em um processo competitivo, em uma espécie de mercado político. As associações mais eficazes tendem a aglutinar mais representados em suas bases, ao passo que aqueles indivíduos que se sentirem desguarnecidos contam com a possibilidade de a qualquer tempo organizar uma nova sociedade de representação. Nos termos de Philippe Schmitter (1974, p. 93-96), a representação pluralista tem como características a organização dos interesses de forma múltipla, voluntária, competitiva, não-hierárquica, autodeterminada e não sujeita a reconhecimento, subvenção ou controle por parte do Estado.

A conformação pluralista é, portanto, o correspondente no lado da demanda de um arranjo administrativo em que a oferta de políticas é organizada de modo formalizado, legalizado e procedimentalizado. É esse modelo de mediação competitiva dos interesses que Richard Stewart descreve em seu clássico trabalho sobre o direito administrativo norteamericano (STEWART, 1975). Refletindo sobre o que seria um modelo adequado de representação compatível com um Estado regulador, Stewart (1975) sustenta que o papel do direito administrativo é o de constituir ambientes de disputa e de rivalidade de interesses, representados por meios formais, no âmbito das agências reguladoras.

Em síntese, a intervenção regulatória é fruto da conjugação da legalização das competências reguladoras e da possibilidade de controle exercida pelo Congresso e pelo Judiciário, a partir da iniciativa dos grupos de interesse. $\mathrm{O}$ resultado desta equação institucional é a configuração de uma burocracia dotada de poder normativo, mas de um poder legislativamente condicionado, politicamente monitorado pela competição dos grupos de interesse, e sujeito a ônus positivos em seu exercício. O poder público não conta com um monopólio da virtude ou com uma supremacia do bem comum, capazes de justificar uma posição de assimetria entre a atuação administrativa e a organização dos indivíduos. A rigor, os poderes de iniciativa são alocados para os particulares, que são encarregados não só dos empreendimentos privados, mas também da mobilização dos recursos políticos para defender suas posições e interesses.

\section{Estado Desenvolvimentista: discricionariedade e hierarquia}

A base jurídica do Estado Desenvolvimentista é constituída por uma governança administrativa caracterizada pelos atributos da discricionariedade e da hierárquica. A discricionariedade representa um tipo de decisão administrativa e um modo de delegação de competências 


\section{DO ESTADO DESENVOLVIMENTISTA AO ESTADO REGULADOR? TRANSFORMAÇÃO, RESILIÊNCIA E COEXISTÊNCIA ENTRE DOIS MODOS DE INTERVENÇÃO}

do Congresso para o Executivo que favorecem as escolhas políticas e as relações informais. A hierarquia, por sua vez, reflete uma forma de interação entre o Estado e sociedade tendente à representação corporativista.

Nessa governança, a discricionariedade conota uma alocação abrangente de poder decisório para a burocracia do Executivo, de forma a habilitar uma atuação sujeita a menores constrangimentos legais sobre os limites da competência delegada. Para a burocracia, o resultado é a obtenção de mandatos amplos, que se estendem sobre uma jurisdição vasta de temas e permitem um manejo de diversos meios administrativos. Para os indivíduos e grupos de interesse a discricionariedade, ao converter as regras gerais em políticas particularizadas a cada caso, enseja uma limitação da participação (ao menos, na forma pluralista) e restringe a possibilidade de contestação judicial das medidas administrativas (UPHAM, 1987, p. 166).

A hierarquia é assim um atributo que decorre da discricionariedade e reforça as suas propriedades. Nesse arranjo, a hierarquia significa a configuração de uma relação assimétrica entre o Estado e a sociedade, segundo a qual as competências decisórias são desproporcionalmente concentradas no Executivo, a quem cabe inclusive selecionar os interlocutores. A combinação da discricionariedade e da hierarquia atribuírem aos formuladores de política a possibilidade de governar o ritmo e a direção da mudança social (UPHAM, 1987, p. 166), que são faculdades críticas para um Estado desenvolvimentista.

Parte desta conformação institucional decorre da composição constitucional da relação entre os poderes. É típico dos Estados desenvolvimentistas a concentração de competências legislativas no Executivo. Com isso, diferentemente do que ocorre no arranjo regulatório, o Congresso não exerce funções governativas ativas e não desempenha, portanto, o papel de principal das delegações de poderes para a burocracia.

Os casos do Brasil e do Japão são dois exemplos dessa dinâmica e ilustram este modo de governança. No caso do Japão, Johnson (1982, p. 50) assinala que o Congresso, ao longo do processo de catch up, nunca desempenhou um papel de mediador entre o Estado e a sociedade, de forma a procurar soluções de compromisso entre os interesses privados e as disposições oficiais. O Congresso atuava como um chancelador de decisões tomadas nos verdadeiros loci decisórios, isto é, os conselhos de Estado, que reuniam as lideranças políticas, a burocracia e os representantes das grandes empresas (JOHNSON, 1982, p. 47-48). 


\section{REVISTA ESTUDOS INSTITUCIONAIS}

O modelo constitucional brasileiro também tem estabelecido uma configuração parlamentar deferente ao Executivo, que reúne amplos poderes de agenda, na proposição e na administração das leis. De um lado, as Constituições de 1967 e a de 1988 garantiram ao Executivo o poder de decreto, por meio do Decreto-Lei (1967) ou da Medida Provisória (1988). Embora a configuração de 1967 seja menos relevante porque a deferência do Congresso também se explicava pelo regime autoritário, é notável que a organização de 1988 preservou a assimetria de poderes entre o Executivo e o Congresso. Além do poder de decreto, o Executivo ainda detém a competência de propor a lei orçamentária e controlar a sua execução. Essa condição reforça o poder de agenda do Executivo, na medida em que mesmo os temas formulados pelo Legislativo dependem da administração orçamentária executiva para serem efetivamente implementados.

A concentração de competências no Executivo, seu poder de decreto e de manejo orçamentário resultam em menores incentivos para o exercício da capacidade legislativa pelo Congresso. Em uma análise sobre o caso brasileiro, Susan Gaylord (2010) assinala que elaborar leis é uma atividade custosa, que envolve tempo de dedicação, tanto técnico, como de negociação política, de forma que o interesse por esta atividade é sopesada em função de seus custos e benefícios. Em razão da prevalência do Executivo na administração orçamentária, há menores incentivos para que os congressistas desempenhem um papel de legisladores, afinal as políticas legisladas podem não ser implementadas em função das possibilidades de contingenciamento orçamentário.

Uma das consequências de escolhas constitucionais que favorecem um Congresso deferente tende a ser a atribuição de competências abertas para a burocracia do Executivo, ou seja, a atribuição de uma discricionariedade deliberada para a administração pública. Upham (1987, p. 169-187) identifica essa característica nas principais leis que governaram a economia japonesa, como a lei de criação do MITI (Ministério da Indústria e do Comércio Internacional), a lei de câmbio e de comércio internacional e a lei de petróleo. Em todos esses casos, Upham (1987, p. 169-187) detecta como traço característico uma delegação ampla, vaga e que não provê parâmetros delineados sobre o exercício da atividade administrativa. Em seus termos: "quando chega-se a questionar quem, quando ou para qual finalidade que o poder deveria ser utilizado, muitas da leis econômicas são tão vagas, que virtualmente não dizem nada".

Essa condição é comparável às delegações de competência para as agências de desenvolvimento brasileiras, como é o caso do BNDES. A legislação atribui uma competência ampla para o Banco, disciplinando-o 


\section{DO ESTADO DESENVOLVIMENTISTA AO ESTADO REGULADOR? TRANSFORMAÇÃO, RESILIÊNCIA E COEXISTÊNCIA ENTRE DOIS MODOS DE INTERVENÇÃO}

na Lei do Sistema Financeiro Nacional - Lei n.. 4.595/64 como o "agente de financiamento das políticas do governo federal". Essa característica ganha realce quando a delegação de competência do BNDES é comparada com a de outros bancos de desenvolvimento, como o banco do Canadá ou do Chile (SCHAPIRO, 2017). Enquanto estes últimos têm mandatos estreitos, contando inclusive com prazo de validade para a sua atuação (caso do Canadá), o BNDES, assim como o MITI, conta com amplas faculdades discricionárias. É ainda revelador desta configuração deferente o fato de que a lei do Sistema Financeiro Nacional e a sua disposição aberta sobre o BNDES, embora sejam de 1964, foram recepcionadas pela Constituição de 1998. Isto é, mesmo após 30 anos de democracia, os legisladores não avocaram a competência de estabelecer regras para as políticas de fomento do banco, nem substantivas, respeitantes à sua competência, nem processuais, acerca de seu processo decisório.

As agências reguladoras no Japão e no Brasil são também casos que ilustram esse deslocamento de poderes para o Executivo e a primazia de certa discricionariedade sobre a legalidade. Diferentemente do modelo regulatório norte-americano, em ambos os países as agências figuram mais como órgãos materialmente delegados do Executivo, do que vinculados à delegação parlamentar (PRADO, 2010; OHNESORGE, 2006).

Ao analisar o caso das agências reguladoras japonesas, Ohnesorge (2006, p. 119-120) indica que, embora tenham sido estabelecidas no pósguerra pelas autoridades dos EUA, as agências foram convertidas ao longo do tempo em conselhos consultivos do Executivo. As diferentes jurisdições regulatórias foram incorporadas no âmbito dos ministérios, seguindo a ideia de um governo unificado, levando assim a perda de identificação das diferentes competências administrativas. No caso brasileiro, Prado (2010) assinala que os poderes de alocação e de contingenciamento orçamentário, reservados aos Ministérios, representam uma possibilidade franqueada ao Executivo para administrar a atividade regulatória. ${ }^{2}$

\footnotetext{
2 Além disso, as agências brasileiras situam-se em uma organização administrativa cujo marco regulador favorece a dominância do Executivo. O Decreto-Lei 200, de 1967, que disciplina a organização administrativa, prescreve um modelo dispare daquele estabelecido pela agenda da reforma regulatória. Enquanto a reforma pretendeu instituir órgãos preservados da influência política, que seriam competentes para decidir em única e última instância, o desenho do Decreto-Lei 200 estabelece uma cadeia hierárquica, na qual a autoridade final pertence aos Ministérios. Para isso, o DL
} 


\section{REVISTA ESTUDOS INSTITUCIONAIS}

A discricionariedade, decorrente da deferência do Congresso, das leis abertas e da prevalência do Executivo, é reforçada pelas construções doutrinárias do direito público concernentes ao controle da administração pública. A dogmática do direito administrativo dos Estados desenvolvimentistas, embora legalista, favorece as escolhas discricionárias, ao reputá-las como opções de governo que são controláveis apenas de forma adjacente, pela eventual ilegalidade em seu processo decisório ou pela violação a direitos subjetivos. Não há, no entanto, neste sistema ônus positivo para o tomador de decisão motivar as escolhas como sendo adequadas aos fins visados. É como se os temas públicos discricionários só fossem captados pelo radar do direito administrativo se orbitarem a faixa da fraude, do desvio de competência legal, ou da violação dos direitos individuais.

No caso brasileiro, a doutrina é estabelecida em torno de uma oposição binária entre a vinculação legal e a discricionariedade, de forma que os temas não vinculados expressamente pela lei são entendidos como alocados para a escolha do Executivo. A consequência é que, a despeito da aparente constrição da legalidade, todos os temas sujeitos à discricionariedade pertencem ao campo de liberdade administrativa. $\mathrm{O}$ controle da discricionariedade é apenas indireto, sendo conduzido pelos motivos que levaram à decisão administrativa, a assim chamada teoria dos motivos determinantes (DI PIETRO, 2017). Diferentemente do que se passa no modelo legalista adversarial, a administração pública desenvolvimentista não está sujeita a um ônus processual de motivar os seus atos como sendo portadores de uma razoabilidade material (por meio de análises de custo-efetividade, por exemplo), como ocorre no direito inglês em função da doutrina de Wednesburry (WANG, 2017). Tampouco os atos discricionários sujeitam-se com rigor ao rito do processo de "notice and comment", do direito norte-americano, que, como mencionado, pode levar uma decisão da burocracia a ser anulada judicialmente, caso a motivação administrativa não pondere os pontos levantados pelos participantes das consultas e audiências públicas (GERSEN, 2010, p. 342-344; BIGNAMI, 2012, p. 16-20).

A experiência japonesa, no período de catch up, é similar, embora a literatura destaque uma restrição ainda maior do que a verificada no Brasil para o controle judicial dos atos administrativos. Os legitimados a

200 estipula, entre outros, o recurso hierárquico, que habilita a revisão das decisões das autarquias pelo Ministro correspondente. Com base nesse dispositivo, por exemplo, a Advocacia Geral da União firmou o Parecer 051/2006, adotado de forma vinculante pelo Presidente da República, que autoriza recurso hierárquico também para as agências reguladoras, caso suas decisões contrariem políticas públicas. $\mathrm{O}$ parecer reforça assim a primazia do Executivo nas relações regulatórias. 


\section{DO ESTADO DESENVOLVIMENTISTA AO ESTADO REGULADOR? TRANSFORMAÇÃO, RESILIÊNCIA E COEXISTÊNCIA ENTRE DOIS MODOS DE INTERVENÇÃO}

questionar um ato administrativo eram aqueles diretamente afetados pelas medidas, o que era interpretado pelas cortes de forma restritiva (UPHAM, 1987, p. 169-176). Além disso, a atuação da burocracia desenvolvimentista japonesa ocorria por meio de expedientes informais, conhecidos como administrative guidance (JOHNSON, 1982, p. 242-274). Baseados em competências abrangentes, órgãos como o MITI organizavam carteis, estimulavam investimentos e restringiam a capacidade industrial, nos momentos de excesso de oferta, por meio de comandos verbais, acordos e orientações. Tais medidas tinham efeitos concretos na organização econômica, importando em expressivos ganhos e perdas empresariais, entretanto, por não serem medidas formais, não eram passíveis de contestação judicial. Ohnesorge (2006, p. 116-122) e Upham (1987, p. 169-176) destacam que a doutrina japonesa apenas reconhecia como controláveis os atos administrativos concretos, o que habilitava uma gestão informal de incentivos e retaliações, favorecendo a governança discricionária.

A composição de amplas faculdades decisórias e de espaços restritos de controle da discricionariedade está associada a um padrão hierárquico de relacionamento entre o Estado e a sociedade, que não favorece a representação pluralista, típica da governança legalista adversarial. A restrição de acesso ao judiciário para contestar políticas e a centralidade decisória do Executivo restringem o ativismo de grupos situados fora do Estado (UPHAM, 1987, p. 198-204). Em seu lugar, tem assento uma relação público-privada dotada de maior verticalidade organizacional, na forma de pactos e barganhas entre o Estado e os grupos de interesse. Os grupos são chamados e chancelados para participar dos ambientes de deliberação pública, como é o caso das conferências, dos fóruns e das câmaras setoriais.

Neste arranjo, a administração desempenha um papel protagonista também na organização dos interesses, na medida em que os grupos, associações e sindicatos dependem do reconhecimento público para atuar em nome de seus filiados. A esse modo de organização dos interesses a literatura de política denomina por corporativismo. Para Schmitter (1974, p. 93-96), o corporativismo tem como características uma organização de interesses em unidades limitadas, não competitivas, diferenciadas funcionalmente por categorias e legitimadas ou subvencionadas pelo Estado. É essa configuração que Robert Wade identifica na organização desenvolvimentista do nordeste da Ásia (WADE, 2004, p. 24-29). Para o autor, enquanto os Estados Unidos é um exemplo de uma representação pluralista, Coréia do Sul, Taiwan e Japão são exemplos de uma 


\section{REVISTA ESTUDOS INSTITUCIONAIS}

JULHO/DEZEMBRO - ISSN 2447-5467

representação corporativista, que engendrou a direção estatal da economia, por meio de uma concertação público-privada (WADE, 2004, p. 24-29).

Em síntese, o modelo discricionário e hierárquico, que sustenta a intervenção desenvolvimentista, confere poderes de iniciativa para a administração, garantindo-lhe espaços de discricionariedade, e competências para organizar os interesses de modo corporativo. Os poderes de ação e de representação são alocados para o domínio público, de forma que os conflitos de interesse encontrarão suas respostas no aparelho do Estado, seja por decisões administrativas, seja pela composição política alcançada em acordos e negociações corporativas.

\section{DINÂMICAS INSTITUCIONAIS: DIFUSÃO REGULATÓRIA E VARIEDADES DE ESTADO}

Nas últimas décadas, a literatura registrou uma difusão do modelo requlatório, tanto em países desenvolvidos, como em países desenvolvimento, inclusive naqueles em que prevalecera uma intervencão desenvolvimentista (MAIONE, 1997, p. 143-148; LEVIFAUR, 2005, p. 16-19; LEVI-FAUR; IORDANA, 2007; IAYASURIYA, 2011; DUBASH; MORGAN, 2013). Como traco comum, diversos países realizaram reformas institucionais que estabeleceram as bases de um outro tipo de governança econômica. Processadas por meio da promulgação de novas leis e marcos regulatórios, as reformas voltaramse a insular as decisões econômicas do cotidiano da política, a incrementar as garantias dos investidores e a restringir o caráter discricionário das decisões administrativas.

A despeito da matriz global do fenômeno, as mudanças institucionais são processadas no âmbito nacional. Assim, o resultado das reformas não é necessariamente um reflexo direto da difusão global do modelo. $\mathrm{Na}$ dimensão doméstica, fatores de resistência institucional (path dependence), presentes em especial na formulação e na aplicação das regras jurídicas, podem impactar os desenhos institucionais e a governança econômica. Essa pretende analisar estas tensões presentes na reforma regulatória ocorridas no Brasil.

\section{A Dimensão Global das Reformas Regulatórias}

Aproximando a lente de análise, verifica-se que em seu conteúdo, as reformas promoveram o transplante da base jurídica regulatória para países dotados de uma outra base institucional. Nessa linha, para além 


\section{DO ESTADO DESENVOLVIMENTISTA AO ESTADO REGULADOR? TRANSFORMAÇÃO, RESILIÊNCIA E COEXISTÊNCIA ENTRE DOIS MODOS DE INTERVENÇÃO}

da criação de agências de regulação, diversos países promulgaram nos últimos anos leis de processo administrativo, instituíram procedimentos e guias para formalizar a decisão administrativa, estabeleceram regras de transparência para assuntos governamentais, e ampliaram os recursos de accountability, em especial, os judiciais. Esse fenômeno nacional é ainda consentâneo com a profusão do direito administrativo global, igualmente estabelecido em uma base legalista-adversarial, e que tem sido difundido como uma solução institucional para governança das relações internacionais (KINGSBURY; KRISCH; STEWART, 2005).

Em uma análise sobre o panorama europeu dos anos 1980 e 1990, Majone (1997) já havia descrito a propagação do Estado regulador como um fenômeno de adaptação das estruturas institucionais a novas estratégias de política econômica adotadas no continente. Para o autor, a estratégia precedente à governança regulatória, baseada em políticas distributivas keynesianas, que habilitavam o Estado a atuar como um "empregador de última instância", esgotou-se nos anos 1970 (MAJONE, 1997, p. 139-146). Além disso, as regras do Tratado de Maastricht impuseram regras fiscais severas para os países constituintes da União Europeia, o que limitou as possibilidades do ativismo estatal (MAJONE, 1997, p. 139-148). Com isso, no lugar do Estado Positivo, baseado na taxação e na despesa pública, na discricionariedade e na representação corporativista, constituiu-se o Estado regulador, assentando em uma intervenção pública orientada pela formulação de regras, limitado pela delegação legislativa e associado a uma representação pluralista dos interesses (MAJONE, 1997, p. 148-152).

Um diagnóstico semelhante, porém, com uma pretensão mais ampla é apresentado por Levi-Faur $(2005$, p. 27). Para o autor, a partir dos anos 1990 configurou-se uma globalizacão regulatória, que foi constitutiva de uma nova ordem na organizacão do capitalismo - o capitalismo regulatório. Segundo essa abordagem, a nova ordem regulatória é portadora de cinco características principais: (i) a redivisão de trabalhos entre o Estado e a sociedade, em virtude das privatizacões; (ii) a delegacão de poderes no Estado, com um rearranio de forcas entre os políticos e os técnicos; (iii) a proliferação de novas tecnologias e instrumentos de requlacão; (iv) a difusão de mecanismos de autoregulacão, institucionalmente amparados pelo Estado; e (v) o aumento da importância dos experts e das redes internacionais de especialistas na formulacão das políticas públicas. Assim como descrito por Maione (1997), a interpretacão de Levi-Faur também ressalta as características legalistas e participativas deste modo de governança, 


\section{REVISTA ESTUDOS INSTITUCIONAIS}

salientando seus atributos de alteridade, prevalência de parâmetros formais, de regras e de procedimentos de aplicação das regras.

Para Levi-Faur (2005), embora a constituicão da ordem regulatória esteia relacionada com a privatizacão de funcões públicas, sua propagacão supera e se destaca desta agenda. Trata-se, para o autor, de um fenômeno mais abrangente, ocorrido de forma interdependente entre os diversos países, gerando assim um isomorfismo da governanca regulatória. Nessa leitura, a constituicão de agências reguladoras e a adocão de ferramentas de regulacão nas relacões público-privadas foram propagadas dos países do Norte (centro) e dos setores mais afinados com este modo de organizacão (financas), para os países do Sul (periferia) e para os demais setores da economia (infraestrutura e área social). Uma evidência desta convergência seria o crescimento exponencial do número de agências reguladoras, a partir dos anos 1990, mesmo em setores não expostos à privatização, e em países não sujeitos ao neoliberalismo, como Cuba (LEVI-FAUR, 2005, p. 16-19; LEVI-FAUR; JORDANA, 2007, p. 336). Dados de Levi-Faur e Jordana (2007) sobre a América Latina são ilustrativos desta tese, que atesta a mudança do papel do Estado: enquanto, em 1979, a região contabilizava apenas 43 agências reguladoras, na maior parte no setor financeiro, em 2002, registravam-se 134 agências, nos mais diversos setores.

Nessa mesma linha, Jayasuriya (2001) aponta uma reconfiguração na forma de atuação econômica dos Estados nacionais em função dos efeitos da globalização econômica. O autor destaca uma alteração na arquitetura institucional do Estado que deixou de desempenhar uma função de coordenação positiva da economia e passou a realizar uma coordenação negativa. A coordenação positiva atribuía ao Estado um papel ativo na composição das barganhas políticas e na compensação dos grupos de interesse. Trata-se de uma atuação que é característica de Estados encarregados de provisões positivas na ordem econômica, como é o caso dos Estados de bem-estar social europeus e dos Estados desenvolvimentistas, asiáticos ou latino-americanos. Tratando destes últimos, em particular, Evans (1995, p. 20-42) e Chang (1999, p. 196-198) identificam nos Estados desenvolvimentistas as feições desta coordenação ativa, tanto em sua participação na definição da acumulação econômica, como em sua atuação no gerenciamento dos respectivos conflitos distributivos.

Seriam, pois, estas duas características que para Jayasuriya (2001) foram colocadas em xeque pela globalização, em razão de alterações na economia política internacional. A coordenação positiva da economia era possível em um cenário de imobilidade do capital, típico da governança de Bretton Woods, que habilitava os países a conduzirem de forma 


\section{DO ESTADO DESENVOLVIMENTISTA AO ESTADO REGULADOR? TRANSFORMAÇÃO, RESILIÊNCIA E COEXISTÊNCIA ENTRE DOIS MODOS DE INTERVENÇÃO}

autônoma suas políticas monetária e fiscal. A mobilidade do capital, por sua vez, impõe restrições de autonomia para os países, que se veem premidos pela eminente fuga de capitais, o que limitou a sua capacidade de estimular a demanda e ditar o ritmo dos investimentos. No caso dos Estados desenvolvimentistas, a mobilidade internacional de capital significou ainda uma pressão adicional ao modelo da coordenação positiva. Não só os Estados perderam parte de seus instrumentos de estímulo econômico, como também passaram a competir com as possibilidades apresentadas pelo mercado global de capitais. Esse fator mitigou o poder doméstico de barganha, na medida em que o Estado perdeu a sua vantagem comparativa como provedor financeiro e assim deixou de ter ascensão sobre as estratégias privadas de acumulação (JAYASURIYA, 2001, p. 105-109).

$O$ resultado da globalização, nessa visão, foi a retração da coordenação positiva e a consolidação de uma coordenação negativa, em que compete ao Estado oferecer as bases institucionais para a ordem de mercado (JAYASURIYA, 2001, p. 109-112). A forma que constitui esta coordenação é a do Estado regulador, que, substitui a gestão corporativa das compensações pela estabilização e pelo insulamento político dos mercados; isso por meio do estabelecimento de regras e procedimentos de intervenção pública (JAYASURIYA, 2001, p. 109-112). Nos termos de Jayasuriya (2001, p. 112): “a provisão de um processo adequado de tomada de decisão administrativa torna-se um fim em si".

\section{A Dimensão Local da Reforma Regulatória}

A despeito de a difusão da ordem regulatória ser um fenômeno global, as mudanças institucionais são sempre processadas no âmbito nacional e convivem com fatores de resistência (path dependence), incorporados muitas vezes nas novas constituições, como é o caso da primazia legislativa atribuída ao Executivo, no caso brasileiro. A resiliência institucional está presente ainda na doutrina jurídica, na aplicação das regras jurídicas pelos tribunais e também na sua mobilização pelos grupos de interesse. A conjugação desses fatores pode impactar os desenhos institucionais e alterar a confecção da governança globalmente difundida. Por essa razão, a despeito do isomorfismo das agências e da convergência regulatória, a anatomia institucional da intervenção estatal adquire formatos institucionais diferentes entre os países e seus setores econômicos. 


\section{REVISTA ESTUDOS INSTITUCIONAIS}

JULHO/DEZEMBRO - ISSN 2447-5467

É isso o que indicam os trabalhos sobre reformas institucionais, ao apresentarem evidencias de que as reformas não são um evento isolado e pontual, mas sim um processo de acomodações permanentes, estabelecidas entre a resiliência do arranjo anterior e a difusão da nova ordem (PISTOR; TURKEWITZ, 1996; PRADO; TREBILCOCK, 2009; ANDREWS, 2013, p. 35-64). No que tange, em especial, às reformas econômicas, Pistor e Turkewitz (1996), em uma análise sobre os países do leste europeu, assinalam que a privatização não é um processo de rodada única, que enseja uma mudança pontual do papel do Estado, representando assim uma passagem definitiva de ativos públicos para a gestão privada. As experiências analisadas pelos autores têm como traço comum e universalizável o caráter processual da privatização, isto é, a privatização é melhor descrita como um processo de estabilização entre a propriedade estatal e a privada, que admite diferentes acomodações e oscilações ao longo do tempo (PISTOR; TURKEWITZ, 1996, p. 192-194).

A base jurídica nacional pode representar um fator de resistência ou de impulso para os modelos regulatórios difundidos internacionalmente. A razão para isso reside no fato de que o direito é uma instituição cognitiva (MEANS, 1980) e que guarda uma relativa autonomia em relação à economia e à política. Isso significa que o seu funcionamento depende da forma como os modelos recebidos são entendidos pelos aplicadores das regras, pelos cidadãos, e pelos formuladores das normas nacionais subsequentes (PISTOR, 2000, p. 08-09). Em outros termos, o sentido do direito e de suas categorias não é estabelecido de forma axiomática, isento de controvérsias interpretativas processadas no sistema de justiça. A estabilização do direito em uma dada sociedade decore de um processo dialógico, estabelecido entre as normas postas e a atuação dos profissionais: advogados, juízes, promotores e os juristas.

Sendo assim, a resiliência de um arranjo institucional é uma função da disparidade entre o propósito desejado pelas reformas e o sentido vigente no direito local. O êxito reformista, por sua vez, representa uma convergência entre os sentidos de ambos os sistemas, o que habilita a efetividade da transformação jurídica pretendida.

As condições locais de resistência e de mudança têm sido analisadas pela literatura de reformas jurídicas, que apresenta evidências sobre as condições de realização dos transplantes institucionais. Em um trabalho sobre as reformas legais em 49 países, Berkovitz, Pistor e Richard (2003) apresentaram dados que relacionam o êxito dos transplantes à ocorrência de adaptações locais e à familiaridade institucional preexistente. No primeiro caso, a importação de modelos conta com adaptações ao funcionamento da base jurídica nacional, o que mitiga as chances de uma rejeição entre o direito transplantado e o direito nacional. No segundo 


\section{DO ESTADO DESENVOLVIMENTISTA AO ESTADO REGULADOR? TRANSFORMAÇÃO, RESILIÊNCIA E COEXISTÊNCIA ENTRE DOIS MODOS DE INTERVENÇÃO}

caso, a base jurídica nacional já apresentava dispositivos familiares àqueles introduzidos pelas reformas.

No caso específico da difusão regulatória, os fatores de resistência e de confirmação das mudanças estão relacionados com a recepção do legalismo adversarial. Isto é, a adoção de um padrão formalizado e procedimentalizado de decisão administrativa e o estabelecimento de uma relação público-privada aberta à participação e à contestação dos grupos de interesse nas decisões administrativas. Para isso, importam as condições preexistentes capazes de habilitar a restrição da discricionariedade administrativa e de promover as possibilidades de controle da administração, sobretudo por meio do judiciário.

A primeira condição preexistente, relativa à restrição da discricionariedade, tem relação com o balanço de poderes decisórios que é constitutivo das respectivas ordens econômicas. Tais poderes podem ser alocados para os particulares ou para o Estado. Enquanto a alocação de poderes para o Estado está atrelada a maior amplitude discricionária, a atribuição de poderes aos particulares tem como corolário uma menor propensão de poderes discricionários (PISTOR; WELLONS, 1995). Essa decisão constitutiva da ordem econômica pode exercer um papel de resistência (path dependence) ou de impulso para as reformas voltadas a reduzir a discricionariedade. Isto é, países com maior balanceamento público-privado podem ter mais familiaridade como um modelo tendente a confinar a discricionariedade do que aqueles em que o Estado reserva mais poderes de direção econômica.

Essa primeira decisão de fundamento constitucional, relacionada a "quem decide?", está associada a uma segunda condição local que diz respeito a como o direito local habilita a burocracia a decidir: "como a burocracia decide?". As normas, a doutrina e a jurisprudência podem contar com princípios mais receptivos de restrições da discricionariedade ou podem estar familiarizadas com categorias que favoreçam a liberdade de decisão administrativa. $O$ êxito do transplante do legalismo adversarial tende a ser maior quanto mais adaptado estiver o direito local a garantir a participação dos indivíduos e a sujeitar os administradores públicos a ônus positivos de motivação de suas decisões. O próprio caráter processual assumido pela organização administrativa norteamericana é uma evidência disso, como relata Bignami (2012). Para a autora, o devido processo administrativo, característico do legalismo adversarial, é um desdobramento dos princípios de justiça natural do direito inglês, dos quais fazia parte o "direito de ser ouvido" pelo Estado. 


\section{REVISTA ESTUDOS INSTITUCIONAIS}

JULHO/DEZEMBRO - ISSN 2447-5467

As formas de exercício da discricionariedade estão associadas a um segundo elemento institucional local, igualmente relevante para a difusão regulatória: a condição de controle da administração, sobretudo a que é exercida pelo judiciário. O controle judicial, ao estipular as condições de motivação e o sentido de devido processo a ser empregado nas decisões e atos administrativos, pode estabelecer constrangimentos positivos para a discricionariedade da burocracia. A depender do tipo de resposta judicial, o processo administrativo pode ser mais ou menos sujeito à participação dos interessados e esta participação pode ser mais ou menos relevante para justificar a decisão da burocracia.

Para isso, três condições jurídicas despontam como relevantes: o desenho do judiciário; a distribuição de legitimidade para as partes processuais e o sentido emprestado para a revisão judicial dos atos administrativos. O desenho do judiciário diz respeito às garantias de autonomia institucional dos magistrados. Sistemas com mais garantias permitem aos juízes revisarem os atos administrativos e favorecem assim a litigância privada como forma de contestação das políticas públicas. A distribuição da legitimidade processual corresponde a amplitude de atores que é habilitada a recorrer ao judiciário. Por último, essas condições são combinadas com o sentido que a jurisprudência empresta para a revisão dos atos administrativos. O Judiciário pode entender que os atos são decisões de especialistas e assim ser deferente ao Executivo ou pode considerar que os atos são plenamente passíveis de revisão, situação em que avoca competências decisórias sobre as políticas.

Os sistemas com mais garantias institucionais, com maior abertura para ações coletivas e com menor deferência ao Executivo são aqueles que mais favorecem a recepção da legalidade regulatória. Já os arranjos em que os juízes são premidos por razões políticas ou econômicas, em que as ações coletivas são restringidas e em que a jurisprudência é deferente à discricionariedade do Executivo tendem a opor mais restrições à difusão do legalismo regulatório e consequentemente à substituição da intervenção desenvolvimentista.

Por essas razões, atinentes aos fatores locais, de impulso e de resistência, as novas evidências da literatura sobre a reforma regulatória e o Estado regulador, notadamente no sul global, sugerem interpretações menos conclusivas sobre a transição realizada. Diferentemente da primeira onda de trabalhos sobre o tema, as publicações mais recentes têm identificado uma variedade de Estados reguladores (YEUNG, 2010). As diferenças decorrem das trajetórias históricas, das tensões políticas e das acomodações nas respectivas bases jurídicas. Tais fatores conformam uma diversidade de composições estatais, que são menos claras do que 


\section{DO ESTADO DESENVOLVIMENTISTA AO ESTADO REGULADOR? TRANSFORMAÇÃO, RESILIÊNCIA E COEXISTÊNCIA ENTRE DOIS MODOS DE INTERVENÇÃO}

as indicações de uma transição de um Estado Positivo para um Estado Regulador, como sugeria Majone (1997).

O argumento da variedade de Estados Reguladores é apresentado por Yeung (2010) em uma comparação entre três economias desenvolvidas: Estados Unidos, Reino Unido e União Europeia. A autora descreve as variedades como decorrentes das diferentes causas e consequências associadas ao desenvolvimento da regulação em cada um desses ambientes. Embora o Estado regulador detenha características analíticas comuns, como descrito nas seções anteriores, a sua constituição é um fenômeno com características locais (YEUNG, 2010, p. 75-76). É o caso das diferenças de trajetória entre o modelo norte-americano, no qual a constituição da regulação representou um aumento de intervenção estatal na economia, e o modelo inglês, em que as agências foram estabelecidas em oposição às empresas estatais então prevalecentes (YEUNG, 2010, p. 75-76), representando uma diminuição dos controles hierárquicos. A ênfase nas variedades regulatórias, em detrimento da ideia de convergência, reforça, portanto, os limites das narrativas generalizantes da primeira onda de trabalhos, orientados para a descrição de uma espécie de processo evolutivo regulatório.

Em um trabalho mais recente, Levi-Faur (2013) aproxima-se desta abordagem e apresenta o argumento de que o Estado capitalista é uma organização polimórfica, isto é, é um arranjo que apresenta diferentes formas em uma mesma configuração política. Ao invés de descrever o Estado regulador como um modo de governança substituto de outras versões rivais, como o Estado de bem-estar ou o Estado desenvolvimentista, Levi-Faur (2013) sustenta que estas formas convivem em uma configuração institucional, que é dotada de diferentes centros irradiadores. Em outros termos, a composição do Estado não é unidimensional, suas acomodações institucionais, similares às composições de uma barreira de corais (KNUSDED; ROTHSTEIN, 1994), são variáveis, resultando assim em uma diversidade de modelos de intervenções estatais, o que é, aliás, compatível com a noção de variedades de capitalismos (HALL; SOSKICE, 2001).

Uma destas variedades é justamente a conformação do Estado regulador nos países do sul global, isto é, nos países em desenvolvimento. Ao tratar do surgimento da governança regulatória nestes países, Dubash e Morgan (2013) identificam três características comuns: (i) a regulação decorreu de um transplante institucional de países desenvolvidos; (ii) as condições sociais dos países em desenvolvimento, notadamente a baixa renda, impõe maior politização da regulação e (iii) há uma interface 


\section{REVISTA ESTUDOS INSTITUCIONAIS}

constante entre o Estado regulador e o Estado desenvolvimentista. Tendo em conta essas características, pode-se entender que, a despeito dos efeitos da globalização elencados Jayasuriya (2001), a coordenação positiva da economia ainda é um traço característico em boa parte destes países. Como já assinalado, nas últimas décadas as políticas industriais e o capitalismo de Estado, que são termos sinônimos dos Estado desenvolvimentistas, ganharam vigor e atraíram a atenção dos analistas, seja na América Latina ou na Ásia, notadamente na China.

Nos termos da análise empregada neste trabalho, o polimorfismo do sul global e as diferentes acomodações entre o Estado regulador e o Estado desenvolvimentista são resultado dos movimentos de resiliência e de impulso processados no plano da base jurídica doméstica. Em outros termos, o saldo dos transplantes será sempre um resultado da organização jurídica dos países, que pode ser mais ou menos receptiva aos modelos reformistas.

Em síntese, há evidências que indicam, nas últimas duas décadas, uma difusão internacional da governança regulatória, assentada em uma base legalista adversarial. Esse movimento, no entanto, tem sido acompanhado de um outro vetor, constituído pela base jurídica local, e que pode confirmar a difusão ou opor resistências às reformas regulatórias. É desse balanço entre o modelo propagado e a configuração jurídica local que resultam os diferentes equilíbrios na organização do Estado.

\section{TRANSFORMAÇÃO, RESILIÊNCIA E COEXISTÊNCIA: MODELOS DE COMPREENSÃO DAS REFORMAS REGULATÓRIAS}

A difusão global de formas regulatórias e a existência de fatores jurídicos domésticos tendentes à resistência (ou à mudança) conformam o resultado das reformas regulatórias, que por isso podem apresentar diferentes equilíbrios institucionais. Em termos analíticos, esses diferentes equilíbrios podem ser descritas como transformação, resiliência e coexistência (TRUBEK; TRUBEK, 2007). ${ }^{3}$

\footnotetext{
${ }^{3}$ A caracterização da coexistência regulatória neste trabalho sustenta-se na tipologia que Trubek e Trubek desenvolveram para analisar as relações entre as regras tradicionais de comando e controle e os novos dispositivos da regulacão por governanca. Naquela análise, os autores tratam de dois tipos de coexistência: a complementaridade e a rivalidade. A complementaridade traduz uma convivência de dois regimes simultâneos que trabalham para um obietivo de política comum. Tá a rivalidade conota uma relação de alternância, em que cada regime procura alcançar objetivos de política de forma independente e potencialmente rival.
} 


\section{DO ESTADO DESENVOLVIMENTISTA AO ESTADO REGULADOR? TRANSFORMAÇÃO, RESILIÊNCIA E COEXISTÊNCIA ENTRE DOIS MODOS DE INTERVENÇÃO}

No primeiro cenário - transformação - a reforma encontra uma base jurídica favorável e disso resulta um alinhamento tendente à transformação do status quo. Nesse caso, há a substituição da base jurídica anterior pelo modelo introduzido pela reforma.

A segunda possibilidade é a resiliência, isto é, a ocorrência de resistências jurídico-institucionais às mudanças engendradas pelas alterações legislativas. Nessa circunstância, os fatores de "path dependence", como a doutrina, a jurisprudência e as condições constitucionais são mais proeminentes do que os fatores de mudança. Com isso, o transplante tende à rejeição e reforma regulatória ainda que ocorra tem o seu funcionamento registrado apenas no plano formal, mas não alcança uma mudança substantiva da governança econômica.

A terceira configuração é a de coexistência, ou seja, uma configuração híbrida, que é caracterizada por relações de preservação do antigo regime e de introdução dos novos atributos. Desta dinâmica podem resultar três cenários: (i) a reforma incremental, que culmine na transformação gradual do arranjo anterior; (ii) a resistência incremental, que provoque uma rejeição progressiva do transplante introduzido pela reforma, ou (iii) uma acomodação persistente das duas ordens, que podem apresentar relações reciprocas de competição e de complementaridade.

Figura 1 - modelo de compreensão das reformas regulatórias

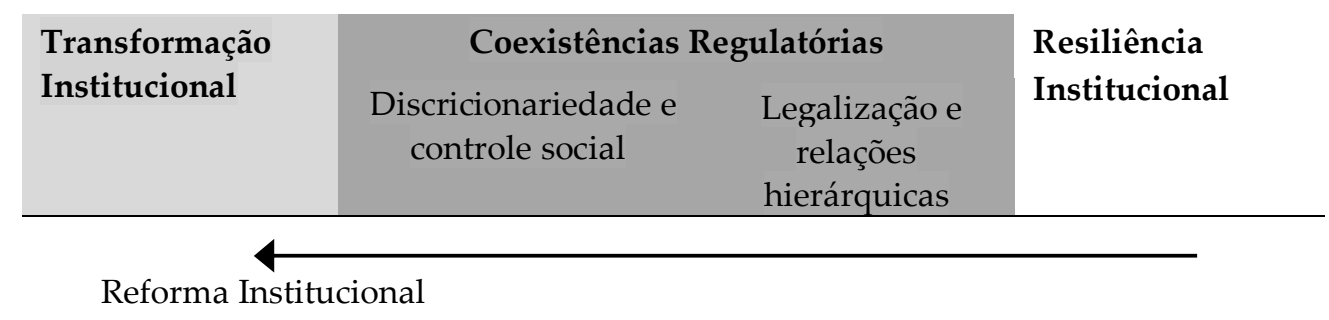

Fonte: Elaborado pelo autor.

$\mathrm{Na}$ análise em questão, transformação, resiliência e coexistência traduzem as diferentes formas de relação entre a intervenção desenvolvimentista e a reforma regulatória. No caso de transformação, o modelo regulatório passa a ser hegemônico, ditando assim um modo de governança das relações econômicas que é baseado em uma organização de tipo legalista adversarial. Neste caso, as decisões da administração passam a ser condicionadas por balizas legislativas, substantivas e 


\section{REVISTA ESTUDOS INSTITUCIONAIS}

processuais, e a atuação reguladora ocorre por meios formais, como regras ou contratos. Esta atividade é ainda sujeita ao controle social, por meio de processos de consulta e audiências públicas, e a arena judicial torna-se um espaço importante de contestação das políticas públicas.

No caso de resiliência, os atributos da base jurídica anteriores à reforma regulatória são preservados, de forma que a discricionariedade e a hierarquia prevalecem como fundamentos do arranjo administrativo. Com isso, a intervenção econômica tende à alternativa desenvolvimentista. As decisões da administração são amparadas em delegações abertas, habilitadoras de escolhas políticas tomadas com liberdade, e contam com menor intensidade de constrangimentos sobre as opções de mérito. Verifica-se ainda restrições de participação dos indivíduos e grupos interesse nas deliberações para as quais não foram convidados. O controle judicial das decisões políticas é igualmente limitado.

Por último, no arranjo de coexistência os atributos da difusão regulatória convivem com as dotações institucionais desenvolvimentistas. Neste caso, pode-se vislumbrar dois tipos de coexistência: (i) a adoção da legalização no lugar da discricionariedade com a manutenção das relações hierárquicas e (ii) a adoção das relações participativas com a preservação da discricionariedade. No primeiro caso, a burocracia atua em termos formais e é limitada pela legalidade, mas sem que isso habilite uma participação social substantiva. E como se a intervenção econômica se assemelhasse a atuação de uma burocracia fiscal, que cobra impostos estipulados em lei, mas não partilha com os indivíduos a formulação da política tributária. No segundo caso, os tomadores de decisão não se colocam em uma relação de hierarquia com os interlocutores, mas reservam faculdades discricionárias. Nesse arranjo, a intervenção econômica estaria próxima de uma atuação diplomática, em que há liberdade decisória conjugada com negociações entre as partes.

A próxima seção ilustra um caso de reforma regulatória associado a fatores locais de resistência institucional. Parcelas do sistema financeiro brasileiro foram objeto de reformas aiustadas com a difusão regulatória global. No entanto, a governanca destes setores parece estar situada em um arranio de coexistência regulatória, situada entre a discricionariedade (arranjo anterior) e a transformação institucional (objetivo das reformas). 


\section{DO ESTADO DESENVOLVIMENTISTA AO ESTADO REGULADOR? TRANSFORMAÇÃO, RESILIÊNCIA E COEXISTÊNCIA ENTRE DOIS MODOS DE INTERVENÇÃO}

\section{O EXEMPlo das Reformas Regulatórias no Sistema FINANCEIRO}

A organizacão institucional dos sistemas de financiamento de atividades críticas contou usualmente com ampla participacão do Estado, notadamente. nos países em desenvolvimento. Nestes, os mercados financeiros são mais frágeis, econômica e institucionalmente. ${ }^{4}$ No âmbito econômico, verifica-se nestas economias uma menor dimensão dos mercados de crédito e de capitais, em relacão ao PIB nacional, além de se constatar restricões de liquidez nas bolsas de valores. No âmbito institucional, a vulnerabilidade econômica é acompanhada pela fragilidade das regras do iogo que governam as decisões financeiras. Como traco comum a muitos destes países, não só as regras de protecão dos investidores indicam debilidades em seu no plano normativo (nível dos marcos requlatórios), como principalmente padecem de constrangimentos em relação à sua efetividade (enforcement).

Além destas fragilidades gerais, há também especificidades ínsitas ao financiamento das atividades selecionadas. Em comum, todos estes setores importam para o desenvolvimento econômico, iá que apresentam elevadas externalidades positivas, em funcão de seu impacto no nível de investimento, na geracão de renda e no aumento da produtividade econômica. Isso sem contar seus efeitos sobre o desenvolvimento humano, associados, entre outros, à moradia, alimentação, mobilidade e educação.

Ocorre, contudo, que tais atividades são marcadas pela dificuldade que impõem aos sistemas financeiros. De um lado, habitacão, infraestrutura e agricultura apresentam um problema de descasamento entre a necessidade dos recursos e a capacidade de pagamento dos tomadores, levando ao que a literatura chama de mismatch financeiro (STIGLITZ, 1991). De outro lado, a inovacão envolve muito risco e incerteza, em virtude da alta taxa de fracassos associada a criacão de novos produtos e processos (FREEMAN; SOETE, 1999). A consequência

\footnotetext{
${ }^{4}$ A análise da fragilidade institucional dos países em desenvolvimento é bastante difundida. Entre os trabalhos que trazem diagnósticos empíricos a respeito, ver os trabalhos da literatura de Law and Finance, em especial La Porta et al. (1998) e La Porta, Lopez-De-Silanes, Sheleifer (2002). Para uma análise crítica da literatura de Law and Finance e uma abordagem de que as finanças são hierárquicas e assimétricas entre os países, ver Pistor (2013). Para uma descrição das debilidades institucionais, com ênfase no financiamento habitacional, ver Chiquier, Hassler e Lea (2004).
} 


\section{REVISTA ESTUDOS INSTITUCIONAIS}

de ambos os problemas é a eventual insuficiência de recursos necessários para amparar as decisões de investimento.

Assim, seia para contornar as fragilidades nacionais, seia para superar as falhas de mercado destas atividades, os governos de diversos países constituíram arranios institucionais dotados de ampla participacão estatal, ${ }^{5}$ como forma de viabilizar um volume satisfatório de recursos. Nessa configuracão, dois instrumentos foram mais difundidos: os dispositivos proprietários e os dispositivos normativos. Os proprietários referem-se ao controle acionário sobre os ativos financeiros, como é o caso da criacão de bancos públicos e empresas estatais. Os dispositivos normativos dizem respeito às regras de direcionamento do crédito, que incidem inclusive sobre os bancos privados. Em síntese, neste modelo de organizacão financeira, o papel do Estado não é apenas o de estabelecer e fazer cumprir a ordem iurídica, mas principalmente $\mathrm{o}$ de operacionalizar crédito e capitais, por meios diretos e indiretos. ${ }^{6} \mathrm{Em}$ síntese, uma atuação típica de Estado Desenvolvimentista.

Nas últimas décadas, no entanto, reformas institucionais ocorridas em diversos países procuraram mitigar o caráter discricionário da organização financeira. Tais reformas, processadas por meio da promulgação de novas leis e marcos regulatórios, voltaram-se a incrementar as garantias dos investidores e a eliminar as barreiras regulatórias para os investimentos estrangeiros. ${ }^{7}$

O financiamento habitacional é um dos mais paradiomáticos exemplos das iniciativas de mudanca institucional. Em parte considerável dos países, os circuitos financeiros originalmente fechados e alinhados ao Estado foram desregulados e orientados para uma aproximacão com os canais de financiamento do mercado de capitais. Dados de Bucklev, Chiquier e Lea (2009, p. 03-04) indicam que o mercado de hipotecas apresentou um crescimento exponencial, nos últimos anos. $\mathrm{Na}$ China e na Índia, os indicadores sugerem um crescimento anual de cerca de $30 \%$, algo não muito diferente do ocorrido nos países bálticos e na Hungria (BUCKLEY; CHIQUIER; LEA, 2009, p. 03-04). A seguinte

\footnotetext{
${ }^{5}$ A literatura institucionalista sobre desenvolvimento apresenta as diversas engrenagens constituídas pelos governos para amparar as estratégias nacionais de crescimento e transformação econômica. Sobre isso, Wade (2004) e Evans (1995). Para uma visão geral a respeito, ver Amsden (2001).

6 Sobre o papel do Estado na orientação das políticas públicas financeiras, ver Stiglitz e Uy (1996). Sobre os modelos de financiamento utilizados no setor habitacional, ver Green e Wachter, (2007).

${ }^{7}$ Esse registro foi acompanhado pela literatura. Entre os principais trabalhos, ver Caprio, Atiyas e Hanson (1996); Pistor, Raiser e Gelfer (2000); Stallings e Studart, (2006).
} 


\section{DO ESTADO DESENVOLVIMENTISTA AO ESTADO REGULADOR? TRANSFORMAÇÃO, RESILIÊNCIA E COEXISTÊNCIA ENTRE DOIS MODOS DE INTERVENÇÃO}

passagem de Green e Wachter, relativa ao setor habitacional é ilustrativa deste movimento:

Historically, housing finance has been provided by heavily regulated local lenders and by government run entities. Mortgage finance was not funded by international capital flows. Today, the integration of housing finance into capital markets is a global phenomenon, albeit in varied forms. The deregulation of housing finance and its integration into global financial markets is occurring throughout the world (GREEN; WACHTER, 2007).

Pode-se entender aue a governanca financeira é constituída por alternativas de decisão sobre a política de alocacão financeira e por alternativas de execucão dessa política. Assim, enquanto a configuracão anterior às reformas atribuía a decisão de alocacão ao Executivo e conferia aos meios estatais parte substantiva de sua execucão (por meio de bancos públicos, p.ex.), o modelo das reformas institucionais tem como horizonte o deslocamento das decisões para os investidores e a sua execucão para o âmbito da propriedade privada. Em termos tipológicos, nesse deslocamento, as decisões discricionárias e orientadas por motivos de política pública cedem espaco para a legalizacão das transacões financeiras e para o incremento dos direitos de propriedade dos investidores.

Em sintonia com este padrão de mudanças institucionais, o sistema financeiro brasileiro também foi objeto de diversas reformas nos últimos vinte anos, entre 1995 e $2016 .^{8}$ Para além das privatizações dos bancos públicos estaduais, realizadas entre 1995 e 2002, ${ }^{9}$ ocorreram reformas relevantes na organização regulatória de diversas atividades críticas.

Entre os quatro setores mencionados, o que apresentou a reforma mais substantiva foi o habitacional. Em 1997, com a promulgacão da Lei n. o 9.514/97, foi instituído o SFI - sistema financeiro imobiliário. Trata-se de uma mudanca significativa em um arranio que, desde 1964, quando de sua criacão, havia sido concebido como densamente regulado e assentado na atuação de bancos públicos.

\footnotetext{
8 Uma descrição abrangente das reformas é apresentada por Fabiani (2009).

9 Sobre as privatizações dos bancos públicos ver Schapiro (2010, p. 267-274). Ver também Stallings e Studart (2006, p. 222-258).
} 


\section{REVISTA ESTUDOS INSTITUCIONAIS}

JULHO/DEZEMBRO - ISSN 2447-5467

Desde 1964, o financiamento habitacional era governado no âmbito do SFH - sistema financeiro da habitacão, criado pela Lei n. ํㅜ 4.380/64. Em termos sucintos, o SFH contava com aportes de recursos públicos por meio do BNH - banco nacional da habitacão - e, depois de 1986, com recursos administrados pela Caixa Econômica Federal. ${ }^{10}$ Além disso, seus financiamentos eram regulados pelos instrumentos de crédito direcionado, que condicionavam a alocacão dos recursos do SBPE sistema brasileiro de poupanca e empréstimo - ao financiamento habitacional. No exercício de sua competência regulatória, o Conselho Monetário Nacional definia o percentual de recursos depositados nas cadernetas de poupanca que deveriam ser exclusivamente utilizados para essa finalidade. ${ }^{11}$ Por fim, as transacões no âmbito do SFH contavam ainda com recursos obtidos de forma compulsória, por meio do FGTS, e dispunham ainda de uma ampla regulacão de seus contratos, inclusive no que tange às taxas de juros, que eram limitadas a $12 \%$ ao ano. ${ }^{12}$

A criacão do SFI teve o obietivo de alterar as bases institucionais deste arranio financeiro e de favorecer uma ligacão entre os financiamentos imobiliários e as atividades do mercado de capitais. Parte significativa desta proposta contou com a introducão de novos instrumentos financeiros, dispostos nas Leis n. ${ }^{\circ}$ 9.514/97 e 10.931/04, que habilitaram a securitizacão dos investimentos. Entre os novos instrumentos criados, destacam-se: o CRI (certificados de recebíveis imobiliários), a CCI (cédulas de crédito imobiliário) e a LCI (letra de crédito imobiliário) (OTTO, 2015). Para dar viabilidade às transacões de mercado, os marcos legais do SFI reforcaram os direitos de propriedade dos investidores, em especial por meio da extensão da alienacão fiduciária para bens imóveis e da disciplina especial sobre o patrimônio de afetação. ${ }^{13}$ A seguinte passagem de Royer sintetiza o modo de operação do SFI:

o modelo contido no SFI não tem dependência de funding direto ou de direcionamento obrigatório, como o SFH, e procura captar fundos iunto ao mercado de capitais. O SFI prevê, em seu modelo teórico, que o

\footnotetext{
${ }^{10}$ Para uma descricão do SFH, ver Azevedo (1988) e Rover (2009).

${ }^{11}$ Nos termos das resolucões do CMN, os valores excedentes do montante que deveria ser canalizado para o crédito habitacional, seriam depositados pelos Bancos no Banco Central, a taxas de juros desfavoráveis.

12 Sobre o regime do SFH, ver Aragão (1999).

13 A alienacão fiduciária representa uma protecão mais robusta que as hipotecas, em razão da forma de recuperacão do imóvel em caso de inadimplência. O patrimônio de afetacão garante maior seguranca iurídica para os financiadores e adquirentes ante eventuais problemas financeiros das construtoras. Ambos os institutos afiançam o lançamento de títulos e a sua negociação no mercado secundário de valores.
} 


\title{
DO ESTADO DESENVOLVIMENTISTA AO ESTADO REGULADOR? TRANSFORMAÇÃO, RESILIÊNCIA E COEXISTÊNCIA ENTRE DOIS MODOS DE INTERVENÇÃO
}

\begin{abstract}
coracão do sistema seia a captacão de recursos em um mercado secundário de títulos de créditos e recebíveis imobiliários. Para isso conta com instrumentos financeiros destinados a fazer essa ponte entre o mercado de capitais e o mercado imobiliário (ROYER, 2009, p. 100).
\end{abstract}

As bases gerais do SFI, notadamente, a disciplina legal de suas atividades, a proteção dos investidores e a integração com o mercado de capitais, foram replicadas no financiamento da agricultura. Em 2004, foi promulgada a Lei n. - 11.076/04, que estabeleceu um novo marco institucional para o financiamento agrário e introduziu ferramentas financeiras ajustadas à securitização de suas atividades. ${ }^{14}$ Entre outros, estes são os casos do Certificado de Direito Creditório (CDA), da Letra de Crédito do Agronegócio (LCA) e do Certificado de Recebíveis do Agronegócio (CRA).

O modelo então prevalecente havia sido constituído em 1965, por meio da Lei n. ํ 4.829 . Nesta ocasião, foi estabelecido o sistema nacional do crédito rural - SNCR, que provia recursos para o financiamento agrícola de acordo com uma arquitetura institucional similar à do sistema financeiro da habitação - SFH. Assim como no caso do financiamento habitacional, o SNCR baseava-se na atuação de bancos públicos e nos mecanismos de direcionamento do crédito, contando para isso com os recursos acumulados no sistema da poupança. ${ }^{15}$

A mudança realizada, em 2004, com a introdução de novos títulos de financiamento, representou a constituição de uma outra arquitetura financeira na atividade agrária. A partir de então, o credor financeiro, ou seja, aquele que financia diretamente a atividade rural, passou a poder securitizar essas operações por meio do lancamento de títulos no mercado de capitais, que são então lastreados nos direitos creditórios do emissor. Em concreto, essa reforma institucional, assim como no caso do SFI, permitiu a ampliacão e a diversificacão do funding do financiamento rural. A sequinte passagem de Chavenco, resume o teor das mudanças ocorridas no setor:

${ }^{14}$ Para uma descrição da governança do financiamento agrário, em especial de sua reforma, ver Buranello (2015).

${ }^{15}$ Sobre as fases do financiamento agrícola, ver Almeida e Zylbersztajn (2008, p. 270274). 


\section{REVISTA ESTUDOS INSTITUCIONAIS}

JULHO/DEZEMBRO - ISSN 2447-5467

o ineditismo dos instrumentos em destaque se verifica na medida em que os novos títulos passam a franquear aos agentes econômicos envolvidos nas atividades rurais o acesso a um modelo completamente novo de financiamento, permitindo a captacão de poupanca via mercado de capitais, em especial através de fundos de investimento e de investidores institucionais (CHAVENCO, 2015, p. 66)

O passo reformista do setor agrário foi incrementado em 2016, com a promulgacão da Lei n. o 13.331. Inicialmente proposta como medida provisória (n. ํ $725 / 16$ ), a Lei prevê a possibilidade de os títulos serem indexados em outras moedas. De acordo com a exposicão de motivos da então medida provisória, um dos obietivos desta indexacão é favorecer a participacão de investidores estrangeiros, que ficariam assim protegidos de eventuais variações cambiais (BRASIL, 2016).

Os setores de infraestrutura e inovacão, embora não tenham sido obieto de reformas legais profundas, comparáveis às ocorridas nos setores habitacional e agrário, também contaram com novos marcos normativos. Em ambos os casos, as reformas procuraram fomentar as atividades de mercado vis a vis um arranio financeiro assentado na atuacão de bancos públicos, como o BNDES, e agências estatais, como a Finep.

No setor de infraestrutura, em particular, a Lei n. o 12.431/11 disciplinou as debêntures incentivadas de infraestrutura. Subiacente a essa proposta, figura a compreensão de aue as fontes privadas de financiamento são exíguas para a infraestrutura (TORRES FILHO; MACAHYBA, 2012). Nesse panorama, o propósito da Lei foi o de vincular a subscricão de debêntures a benefícios fiscais e assim tornar mais atrativa essa modalidade de financiamento. A inciativa, portanto, foi a de fomentar um mercado privado de dívida e assim diversificar as fontes para além das provisões de bancos públicos e dos investimentos realizados pelas empresas estatais (POMPERMAYER; SILVA FILHO, 2016). A seguinte passagem de Wajnberg sintetiza os propósitos da reforma de 2011:

Assim, com o objetivo de incentivar o mercado privado de financiamento de longo prazo, o governo, por meio da edição da Lei 12.431, em 24 de junho de 2011, criou incentivos tributários para investidores de títulos privados de renda fixa, em especial para investimentos em debêntures simples e cotas de fundos de investimento. Os incentivos tributários incluíram, primeiramente, alíquota zero de Imposto de Renda para 


\title{
DO ESTADO DESENVOLVIMENTISTA AO ESTADO REGULADOR? TRANSFORMAÇÃO, RESILIÊNCIA E COEXISTÊNCIA ENTRE DOIS MODOS DE INTERVENÇÃO
}

\begin{abstract}
rendimentos de debêntures simples adquiridas por investidores estrangeiros, cujos recursos tenham sido captados para serem alocados em projetos de investimento (Artigo $1^{\circ}$ da Lei). Adicionalmente, a lei criou as debêntures de infraestrutura, debêntures simples emitidas com vistas a implementar projetos em setores de infraestrutura considera dos prioritários pelo governo (Artigo 20 ${ }^{\circ}$ da lei) (WAJBERG, 2014, p. 336).
\end{abstract}

Por último, o financiamento do setor de inovacão contou apenas com reformas infralegais, mas com orientacão semelhante aos demais. Tradicionalmente, o financiamento da ciência e tecnologia foi suportado por fundos públicos, tais como o Fundo Nacional de Ciência e Tecnologia. Além de recursos orcamentários, instituicões como o BNDES e a Finep também desenvolveram arranios societários e contratuais que permitiram amparar as apostas em inovação e em empresas emergentes. ${ }^{16}$

A edicão das instrucões normativas 209 e 391, da CVM, procurou estabelecer um marco regulador que favorecesse a captacão de outras fontes para os empreendimentos de private equitu e venture capital. Antes da instrucão normativa 209, os veículos utilizados para estes financiamentos eram sociedades anônimas, cuja forma jurídica trazia desvantagens para os investidores (Carvalho, Ribeiro, Furtado, 2006, pp. 53-61). O problema tem sido contornado com a constituicão de veículos financeiros organizados como condomínios, que replicaram no país uma organizacão iurídica típica da indústria de capital de risco norteamericana - as limited partnerships - LPs. Deste modo, os investidores, que são cotistas dos fundos, contam com uma incidência tributária e níveis de responsabilizacão menores do que aquelas imputados aos sócios de uma empresa. ${ }^{17}$ Desde a edicão das instrucões normativas, o setor tem apresentado um crescimento no volume de capital mobilizado (FGVCEPE, 2008).

A rigor, todas estas reformas estão localizadas em um contexto mais abrangente que abarcou também outras modificacões, institucionais e requlatórias, realizadas com a finalidade de desenvolver os mercados de crédito e de capitais no país. Assim, além dos casos selecionados, o quadro das reformas é composto pela promulgacão de uma nova lei societária (Lei $\mathrm{n}^{\mathrm{o}}$ 10.303/01), pela criacão de níveis de governanca voluntários na bolsa de São Paulo (nível 1, nível 2 e novo mercado), pela

\footnotetext{
${ }^{16}$ A esse respeito, Schapiro (2013).

17 Para detalhes a respeito, Schapiro (2010).
} 


\section{REVISTA ESTUDOS INSTITUCIONAIS}

JULHO/DEZEMBRO - ISSN 2447-5467

alteracão da lei de falências (Lei n.o 11.101/05) e também por iniciativas de racionalizacão dos processos iudiciais (criação da súmula vinculante e lei dos recursos repetitivos, p. ex) (FABIANI, 2009, p. 45-87).

Alguns anos depois destas reformas, no entanto, a configuração institucional resultante no sistema financeiro nacional sugere que não se tenha alcançado por completo um novo modelo de governança financeira. Em boa medida, os resultados parecem confirmar as conclusões apontadas pela literatura sobre reformas institucionais. As análises sobre as reformas convergem na conclusão de que as mudanças institucionais tendem a apresentar resistências, em função da resiliência dos arranjos anteriores. Trata-se, entre outros, da manifestação de uma "path dependence" na organização institucional. ${ }^{18}$

A participacão do SFH é ainda prevalecente. Análises quantitativas realizadas por Martins, Lundberg e Takeda (2011) indicam que os instrumentos mais relevantes de financiamento são os bancos públicos e o crédito direcionado. O estudo aponta ainda que a Lei n. o 10.931/04, apesar de ter incrementado a protecão dos investidores, não apresentou efeito significativo sobre o crédito habitacional.

No setor agrário, dados do Ministério da Agricultura revelam que o sistema nacional do crédito rural ainda responde por $30 \%$ do financiamento do setor (BRASIL, 2016). Mais que isso, os bancos públicos também utilizam as novas ferramentas financeiras criadas pela Lei $\mathrm{n} . \stackrel{\mathrm{o}}{\mathrm{g}}$ 11.076/04, indicando assim uma combinação de arranjos (CHAVENCO, 2015).

O financiamento de infraestrutura, por sua vez, continua dependente dos agentes estatais. As debêntures incentivadas apresentaram um volume de lancamento inferior ao esperado, atingindo um total aproximado de R\$ 5 bilhões (WAIBERG, 2014, p. 333). Dados do BNDES revelam que o banco é a principal fonte de financiamento da infraestrutura no país (WAJBERG, 2014, p. 334).

Finalmente, na indústria de venture capital também se observa uma convivência entre os modelos de financiamento. Os números do FGVCepe, revelam que o BNDES e a Finep são agentes importantes da indústria de fundos, atuando como cotistas, ou seia, são sócios de fundos privados (FGV-CEPE, 2008). Essa participação é ainda mais pronunciada nos segmentos de maiores riscos, como os de empresas emergentes e de capital semente (SCHAPIRO, 2012, p. 283-289).

\footnotetext{
18 Sobre as reformas institucionais e seus limites, ver, entre outros, Andrews (2013) e Prado e Trebilcock (2009).
} 


\section{DO ESTADO DESENVOLVIMENTISTA AO ESTADO REGULADOR? TRANSFORMAÇÃO, RESILIÊNCIA E COEXISTÊNCIA ENTRE DOIS MODOS DE INTERVENÇÃO}

\section{CONCLUSÃO}

Este artigo apresentou, em termos analíticos, duas modalidades de intervenção econômica - o Estado regulador e o Estado desenvolvimentista. Enquanto o Estado Desenvolvimentista é constituído por uma governança administrativa caracterizada pelos atributos da discricionariedade e da hierárquica, o Estado Regulador tem como traço característico uma governança legalizada e sujeita à livre participacão dos grupos de interesse.

Nas últimas décadas, a literatura registrou uma difusão do modelo requlatório, tanto em países desenvolvidos, como em países desenvolvimento, inclusive naqueles em que prevalecera uma intervencão desenvolvimentista. Como traco comum, diversos países realizaram reformas institucionais que estabeleceram as bases de um outro tipo de governança econômica. Processadas por meio da promulgação de novas leis e marcos regulatórios, as reformas voltaramse a insular as decisões econômicas do cotidiano da política, a incrementar as garantias dos investidores e a restringir o caráter discricionário das decisões administrativas.

A despeito da matriz global do fenômeno, as mudanças institucionais são processadas no âmbito nacional. Assim, o resultado das reformas não é necessariamente um reflexo direto das agendas de organismos multilaterais. Na dimensão doméstica, fatores de resistência institucional (path dependence) podem impactar os desenhos institucionais e a governança econômica. A resiliência institucional está presente, entre outros, na doutrina jurídica, na aplicação das regras jurídicas pelos tribunais e também na sua mobilização pelos grupos de interesse. A conjugação desses fatores pode impactar os desenhos institucionais e alterar a confecção da governança globalmente difundida. Por essa razão, a despeito do isomorfismo das agências e da convergência regulatória, a anatomia institucional da intervenção estatal adquire formatos institucionais diferentes entre os países e seus setores econômicos.

Em termos analíticos, os diferentes ajustes entre o modelo regulatório propagado e a configuração jurídica local podem ser compreendidos pelos tipos: transformação, resiliência e coexistência. A transformação traduz uma reforma em que a base jurídica local é favorável e disso resulta um alinhamento tendente à transformação do status quo. A resiliência indica a ocorrência de resistências institucionais às mudanças engendradas pelas alterações legislativas. Nessa circunstância, os fatores de "path dependence", como a doutrina, a jurisprudência e as condições 


\section{REVISTA ESTUDOS INSTITUCIONAIS}

constitucionais são mais proeminentes do que os fatores de mudança. Neste caso, o transplante tende à rejeição e reforma ainda que ocorra tem o seu funcionamento registrado apenas no plano formal, mas não alcança uma mudança substantiva da governança econômica. Por último, a coexistência constitui uma configuração híbrida, que é caracterizada por relações de preservação do antigo regime e de introdução dos novos atributos. Desta dinâmica podem resultar uma reforma incremental, que culmine na transformação gradual do arranjo; uma resistência incremental, que provoque uma rejeição progressiva do transplante, ou uma acomodação persistente das duas ordens, que podem apresentar relações reciprocas de competição e de complementaridade.

O exemplo das reformas financeiras indica resultados de coexistência. Em todos os casos, as novas instituições seguem ladeadas pelos arranjos de caráter desenvolvimentista. Próximas pesquisas podem avaliar a evolução do quadro, isto é, podem analisar se as novas instituições foram capazes de incrementalmente substituir o arranjo anterior, se foram derrotadas pelo vigor das resistências ou se foi estabelecido um equilíbrio com dualidade entre ambos os desenhos.

\section{REFERÊNCIAS}

ALMEIDA, Luciana Florêncio de; ZYLBERSZTAJN, Decio. Crédito Agrícola no Brasil: uma perspectiva institucional sobre a evolução dos contratos. Revista Eletrônica de Negócios Internacionais, v. 3, n. 2, p. 267-287, 2008.

AMSDEN, Alice Hoffenberg et al. The rise of" the rest": challenges to the west from late-industrializing economies. Oxford University Press, USA, 2001.

ANDREWS, Matt. The limits of institutional reform in development: Changing rules for realistic solutions. Cambridge University Press, 2013.

ARAGÃO, José Maria. Sistema financeiro da habitação: uma análise sociojurídica da gênese, desenvolvimento e crise do sistema. Jurua Editora, 1999. 
DO ESTADO DESENVOLVIMENTISTA AO ESTADO REGULADOR? TRANSFORMAÇÃO, RESILIÊNCIA E COEXISTÊNCIA ENTRE DOIS MODOS DE INTERVENÇÃO

AZEVEDO, Sergio de. Vinte e dois anos de política de habitação popular (1964-86): criação, trajetória e extinção do BNH. Revista de Administração Pública, v. 22, n. 4, p. 107-119, 1988.

BERKOWITZ, Daniel; PISTOR, Katharina; RICHARD, Jean-Francois. Economic development, legality, and the transplant effect. European economic review, v. 47, n. 1, p. 165-195, 2003.

BIGNAMI, Francesca. Comparative administrative law. The Cambridge companion to comparative law. Cambridge: The George Washington University Law School, p. 145-70, 2012.

BRASIL. Ministério da Agricultura, Pecuária e Abastecimento e Ministério da Fazenda. Exposição de Motivos Interministerial n. ${ }^{\circ}$ 00033/2016, 2016. Disponível em:

$<$ http://www.planalto.gov.br/ccivil_03/_Ato2015-2018/2016/Exm/ExmMP-725-16.pdf>. Acesso em: 27 de nov. de 2018.

BUCKLEY, Robert; CHIQUIER, Loïc; LEA, Michael. Housing Finance and the Economy. In: CHIQUIER, Loic; LEA, Michael (Ed.). Housing finance policy in emerging markets. The World Bank, 2009.

BURANELLO, Renato. Securitização do Crédito como Tecnologia para o Desenvolvimento do Agronegócio: proteção jurídica do investimento privado. Tese de Doutorado, PUC-SP, 2015.

CAPRIO, Gerard; ATIYAS, Izak; HANSON, James A. (Ed.). Financial reform: theory and experience. Cambridge University Press, 1996.

CARVALHO, Antonio Gledson de; RIBEIRO, Leonardo de Lima; FURTADO, Cláudio Vilar. A Indústria de Private Equity e Venture Capital - primeiro censo brasileiro. São Paulo: Saraiva, 2006, p. 53-61. 


\section{REVISTA ESTUDOS INSTITUCIONAIS}

CHANG, Ha-Joon. The economic theory of the developmental State. In: WOO-CUMMINGS, Meredith (org.). The Developmental State. London: Cornell University Press, 1999.

CHAVENCO, Maurício Rodrigues de Albuquerque. O SNCR e os Novos Instrumentos de Financiamento do Agronegócio: o mercado de crédito rural brasileiro entre dois modelos. 2015. Dissertação de Mestrado, Faculdade de Direito da USP, 2015.

CHIQUIER, Löic; HASSLER, Olivier; BUTLER, Stephen. Enforcement of Mortgage Rights. In: CHIQUIER, Löic; LEA, Michael. Housing Finance Policy in Emerging Markets. Washington: World Bank, 2009.

CHIQUIER, Loïc; HASSLER, Olivier; LEA, Michael. Mortgage Securities in Emerging Markets. The World Bank Policy Research Working Paper n. ㅇ 3370, 2004.

COUTINHO, Diogo. R. ; SCHAPIRO, Mario. G. Economia política e direito econômico: do desenvolvimentismo aos desafios da retomada do ativismo estatal. In: COSTA, José Augusto Fontoura; ANDRADE, José Maria Arruda de; MATSUO, Alexandra Mery Hansen. (Org.). Direito: Teoria e Experiência - Estudos em Homenagem a Eros Roberto Grau. 1 ed. São Paulo: Malheiros, 2013.

DI PIETRO, Maria Sylvia. Direito Administrativo. São Paulo: Atlas, 2017

DUBASH, Navroz; MORGAN, Bronwen. The Rise of the Regulatory State of the South - Infrastructure and Development in Emerging Economies. Oxford, 2013.

DÜBEL, Hans-Joachim; WALLEY, Simon. Consumer Information and Protection. In: CHIQUIER, Löic; LEA, Michael. Housing Finance Policy in Emerging Markets. Washington: World Bank, 2009. 
DO ESTADO DESENVOLVIMENTISTA AO ESTADO REGULADOR? TRANSFORMAÇÃO, RESILIÊNCIA E COEXISTÊNCIA ENTRE DOIS MODOS DE INTERVENÇÃO

EVANS, Peter. Embedded Autonomy - state and industrial transformation. Princeton: Princeton University Press, 1995.

FABIANI, Emerson. Reformas Institucionais no Mercado de Crédito Bancário no Brasil (1999-2006): uma análise jus-sociológica. 2009. Tese de Doutorado, Faculdade de Direito da USP, 2009.

FGV-Cepe. Panorama da Indústria Brasileira de Private Equity e Venture Capital. Relatório de Pesquisa, 2008. Disponível em: $<$ https://bibliotecadigital.fgv.br/dspace/bitstream/handle/10438/13439/Pa norama $\% 20$ da $\% 20$ ind $\%$ C3\%BAstria $\% 20$ brasileira $\% 20 d e \% 20$ Private $\% 20$ Equity\%20e\%20Venture\%20Vapital_2008.pdf?sequence=1\&isAllowed=> . Acesso em: 27 de nov. de 2018.

FREEMAN, Chris; SOETE, Luc. The Economics of Industrial Innovation. 3 ed. Massachusetts: MIT Press, 1999.

GAYLORD, Sylvia. Too Undisciplined to Legislate? Party Unity and Policy-making in Brazil. Journal of Politics in Latin America, v. 4, n. 3, 2012.

GERSEN, Jacob. Designing Agencies: Public Choice and Public Law. Research Handbook in Public Law and Public Choice. Edward Elgar, 2010.

GORDON, Jeffrey; ROE, Mark (Ed.). Convergence and Persistence in Corporate Governance. New York: Cambridge, 2004.

GREEN, Richard; WATCHER, Susan. The Housing Finance Revolution. Research Paper Series. University of Pennsylvania Institute for Law and Economics, 2007. 


\section{REVISTA ESTUDOS INSTITUCIONAIS}

HALL, Paul; SOSKICE, David. Introduction. In: Varieties of capitalism: the institutional foundations of comparative advantage. Oxford University Press, 2011.

JAYASURIYA, Kanishka. Globalization and the changing architecture of the state: the regulatory state and the politics of negative coordination. Journal of European Public Policy, v. 8, n. 1, p. 101-123, 2001.

JAYASURIYA, Kanishka. Beyond institutional fetishism: From the developmental to the regulatory state. New Political Economy, v. 10, n. 3, p. 381-387, 2005.

JAYASURIYA, Kanishka. Regulatory State with Dirigiste Characteristics: Variegated Pathways of Regulatory Governance. In:

DUBASH, Navroz; MORGAN, Bronwen. The Rise of the Regulatory State of the South - Infrastructure and Development in Emerging Economies. Oxford, 2013.

JOHNSON, Chalmers. MITI and the Japanese miracle: the growth of industrial policy: 1925-1975. Stanford University Press, 1982.

LEVI-FAUR, David. The global diffusion of regulatory capitalism. Annals of the American Academy of Political and Social Science, v. 598, p. 12-32, 2005.

LEVI-FAUR, David. The odyssey of the regulatory state: From a "thin" monomorphic concept to a "thick" and polymorphic concept. Law \& Policy, v. 35, n. 1-2, p. 29-50, 2013.

LEVI-FAUR, David; JORDANA, Jacint. Toward a Latin American regulatory state? The diffusion of autonomous regulatory agencies 
DO ESTADO DESENVOLVIMENTISTA AO ESTADO REGULADOR? TRANSFORMAÇÃO, RESILIÊNCIA E COEXISTÊNCIA ENTRE DOIS MODOS DE INTERVENÇÃO

across countries and sectors. Intl Journal of Public Administration, v. 29, n. 4-6, p. 335-366, 2006.

KAGAN, Robert. Adversarial Legalism: the American Way of Law. Cambridge: Harvard University Press, 2001

KINGSBURY, Benedict; KRISCH, Nico; STEWART, Richard B. The emergence of global administrative law. Law and contemporary problems, v. 68, n. 3/4, p. 15-61, 2005.

KNUDSEN, Tim; ROTHSTEIN, Bo. State building in Scandinavia. Comparative politics, p. 203-220, 1994.

LA PORTA, Rafael et al. Law and finance. Journal of political economy, v. 106, n. 6, p. 1113-1155, 1998.

LA PORTA, Rafael; LOPEZ-DE-SILANES, Florencio; SHLEIFER, 609 Andrei. Government ownership of banks. The Journal of Finance, v. 57, n. 1, p. 265-301, 2002.

LEA, Michael. Mortgage Instruments. In: CHIQUIER, Löic; LEA, Michael. Housing Finance Policy in Emerging Markets. Washington: World Bank, 2009.

MAJONE, Giandomenico. From the positive to the regulatory state: causes and consequences of changes in the mode of governance. Journal of public policy, v. 17, n. 2, p. 139-167, 1997.

MARTINS, Bruno; LUNDBERG, Eduardo; TAKEDA, Tony. Housing Finance in Brazil: institutional improvements and recent developments. IDB Working Paper Series n. 269, 2011. 


\section{REVISTA ESTUDOS INSTITUCIONAIS}

MCCUBBINS, Mathew D.; NOLL, Roger G.; WEINGAST, Barry R. Administrative procedures as instruments of political control. Journal of Law, Economics, \& Organization, v. 3, n. 2, p. 243-277, 1987.

MCCUBBINS, Matthew D.; NOLL, Roger G.; WEINGAST, Barry R. Structure and process, politics and policy: Administrative arrangements and the political control of agencies. Virginia Law Review, p. 431-482, 1989.

MEANS, Robert Charles. Underdevelopment and the Development of Law: Corporations and Corporation Law in Nineteenth-Century Colombia. Chapel Hill: University of North Carolina, 1980.

OHNESORGE, John. Understanding Chinese Legal and Business Norms: A Comment on Janet Tai Landa's Chapter. In: APPELBAUM, Richard P. et al. Rules and Networks: The Legal Culture of Global Business Transactions. Oñati International Series in Law and Society, 2001.

OHNESORGE, John et al. LAW AND DEVELOPMENT: PROBLEMS, PERSPECTIVES, AND PROSPECTS. In: American Society of International Law. Proceedings of the Annual Meeting. Cambridge University Press, 2006. p. 423.

OTTO, Samira. Real Estate Policy in Brazil and Some Comparisons with the United States. Stanford Center for International Development Working Paper n. o 549, 2015.

PISTOR, Katharina; RAISER, Martin; GELFER, Stanislaw. Law and finance in transition economies. Economics of transition, v. 8, n. 2, p. 325-368, 2000. 
DO ESTADO DESENVOLVIMENTISTA AO ESTADO REGULADOR? TRANSFORMAÇÃO, RESILIÊNCIA E COEXISTÊNCIA ENTRE DOIS MODOS DE INTERVENÇÃO

PISTOR, Katharina; TURKEWITZ, Joel. Coping with hydra-state ownership after privatization. Corporate Governance in Central Europe and Russia, v. 2, p. 192-244, 1996.

PISTOR, Katharina; WELLONS, Philip. The Role of Law and Legal Institutions in Asian Economic Development, 1960-1995. Oxford University Press, 1995.

PISTOR, Katharina. A Legal Theory of Finance. Journal of Comparative Economics, v. 41, n. 2, 2013.

PISTOR, Katharina. The Standardization of Law and its Effect on Developing Economies. G24 Discussion Papers. United Nations, 2000.

POMPERMAYER, Fabiano Mezadre; SILVA FILHO, Edison Benedito. Concessões no Setor de Infraestrutura: propostas para um novo modelo de financiamento e compartilhamento de riscos. Texto para Discussão Ipea n. $\stackrel{\circ}{2177,} 2016$.

PRADO, Mariana Mota. Presidential Dominance: the Relationship between the Executive Branch and Regulatory Agencies in Brazil. IN:

ROSE-ACKERMAN, Susan; LINDSETH, Peter. (eds.), Comparative Administrative Law. Edward Elgar, 2010.

PRADO, Mariana; TREBILCOCK, Michael. Path dependence, development, and the dynamics of institutional reform. University of Toronto Law Journal, v. 59, n. 3, p. 341-380, 2009.

ROYER, Luciana de Oliveira. Financeirização da Política Habitacional: limites e perspectivas. 2009. Tese de Doutorado, Faculdade de Arquitetura e Urbanismo da Universidade de São Paulo, 2009. 


\section{REVISTA ESTUDOS INSTITUCIONAIS}

SCHAPIRO, Mario. G.; COUTINHO, Diogo. R. Political economy and economic law in Brazil: from import substitution to the challenges of the new state activism. In: BURCA, Grainne de; KILPATRICK, Claire;

\section{SCOTT, Joanne. (Org.). Critical Legal Perspectives on Global} Governance: Liber Amicorum David M Trubek. 1 ed. Oxford: Hart Publishing, 2013.

SCHAPIRO, Mario G. Banco de Desenvolvimento, Regulação e Autorregulação: complementaridade regulatória no mercado brasileiro de capital de risco. In: SCHAPIRO, Mario G.; TRUBEK, David M. (Org.). Direito e Desenvolvimento: um diálogo entre os Brics. 1 ed. São Paulo: Saraiva, 2012.

SCHAPIRO, Mario. G. Legalidade ou discricionariedade na governança de bancos publicos: uma analise aplicada ao caso do BNDES. Revista de Administração Pública (Impresso), v. 51, p. 105, 2017.

SCHAPIRO, Mario G. Novos Parâmetros para a Intervenção do Estado na Economia. São Paulo: Saraiva, 2010.

SCHAPIRO, Mario G. Rediscovering the Developmental Path? Development Bank, Law, and Innovation Financing in the Brazilian Economy. In: TRUBEK, David; ALVIAR, Helena; COUTINHO, Diogo;

SANTOS, Alvaro. (Org.). Law and the New Developmental State: The Brazilian Experience in Latin America Context. 1 ed. New York: Cambridge, 2013.

SCHMITTER, Philippe. Still the Century of Corporatism? The Review of Politics, v. 36, n. 1, 1974. 
DO ESTADO DESENVOLVIMENTISTA AO ESTADO REGULADOR? TRANSFORMAÇÃO, RESILIÊNCIA E COEXISTÊNCIA ENTRE DOIS MODOS DE INTERVENÇÃO

STALLINGS, Barbara; STUDART, Rogerio. Finance for Development Latin America in Comparative Perspective. Washington: Brooking Institution, 2006.

STEWART, Richard B. The Reformation of American Administrative Law. Harvard Law Review, v. 88, n. 8, 1975.

STIGLITZ, Joseph E.; UY, Marilou. Financial markets, public policy, and the East Asian miracle. The World Bank Research Observer, v. 11, n. 2, p. 249-276, 1996.

STLIGTZ, Joseph. Government, Financial Markets, and Economic Development. Working Paper nº. 3669. National Bureau of Economic Research, 1991.

TORRES FILHO, Ernani; MACAHYBA, L. O Elo Perdido: o mercado de títulos de dívida corporativa no Brasil: avaliação e propostas. São Paulo: IEDI, 2012.

TRUBEK, David \& TRUBEK, Louise. New Governance \& Legal Regulation: Complementarity, Rivalry, and Transformation. Columbia Journal of European Law, 2007.

TRUBEK, David; COUTINHO, Diogo. R.; SCHAPIRO, Mario G. Toward a New Law and Development: New State Activism in Brazil and the Challenge for Legal Institutions. In: CISSE, Hassane et al. (Ed.). The World Bank Legal Review: Legal Innovation and Empowerment for Development. The World Bank, 2013.

UPHAM, Frank. Law and Social Change in Postwar Japan. Harvard, 1987. 


\section{REVISTA ESTUDOS INSTITUCIONAIS}

WADE, Robert. Governing the market: economic theory and the role of government in East Asian industrialization. New Jersey: Princeton Press, 2004.

WAJBERG, Daniel. Debentures de Infraestrutura: emissões realizadas e perspectivas. Revista do BNDES, v. 41, 2014, p. 336.

WANG, Daniel Wei L. From wednesbury unreasonableness to accountability for reasonableness. The Cambridge Law Journal, v. 76, n. 3, p. 642-670, 2017.

YEUNG, Karen. The Regulatory State. In: BALDWIN, Robert; CAVE, Martin; LODGE, Martin. The Oxford Handbook of Regulation, Oxford, 2010. 